\title{
Effects of Two Purification Pretreatments on Electroless Copper Coating over Single-Walled Carbon Nanotubes
}

\author{
Zhong Zheng, ${ }^{1}$ Lianjie Li, ${ }^{1}$ Shijie Dong, ${ }^{1}$ Anchun Xiao, ${ }^{2}$ Shixuan Sun, ${ }^{3}$ and Sinian Li ${ }^{1}$ \\ ${ }^{1}$ Hubei Provincial Key Laboratory of Green Materials for Light Industry, Hubei University of Technology, Wuhan 430068, China \\ ${ }^{2}$ School of Science, Hubei University of Technology, Wuhan 430068, China \\ ${ }^{3}$ Capital Aerospace Machinery Corporation, Beijing 100076, China
}

Correspondence should be addressed to Zhong Zheng; zhengzh215@163.com and Shijie Dong; dongsjsj@163.com

Received 11 October 2014; Revised 14 December 2014; Accepted 14 December 2014; Published 29 December 2014

Academic Editor: Renyun Zhang

Copyright (C) 2014 Zhong Zheng et al. This is an open access article distributed under the Creative Commons Attribution License, which permits unrestricted use, distribution, and reproduction in any medium, provided the original work is properly cited.

\begin{abstract}
To achieve the reinforcement of copper matrix composite by single-walled carbon nanotubes, a three-step-refluxing purification of carbon nanotubes sample with $\mathrm{HNO}_{3}-\mathrm{NaOH}-\mathrm{HCl}$ was proposed and demonstrated. A previously reported purification process using an electromagnetic stirring with $\mathrm{H}_{2} \mathrm{O}_{2} / \mathrm{HCl}$ mixture was also repeated. Then, the purified carbon nanotubes were coated with copper by the same electroless plating process. At the end, the effects of the method on carbon nanotubes themselves and on copper coating were determined by transmission electron microscope spectroscopy, scanning electron microscope spectroscopy, X-ray diffractometry, thermogravimetric analysis, Fourier transformed infrared spectroscopy, and energy dispersive spectrometry. It was clearly confirmed that both of the two processes could remove most of iron catalyst particles and carbonaceous impurities without significant damage to carbon nanotubes. The thermal stability of the sample purified by $\mathrm{H}_{2} \mathrm{O}_{2} / \mathrm{HCl}$ treatment was slightly higher than that purified by $\mathrm{HNO}_{3}-\mathrm{NaOH}-\mathrm{HCl}$ treatment. Nevertheless, the purification by $\mathrm{HNO}_{3}-\mathrm{NaOH}-\mathrm{HCl}$ treatment was more effective for carboxyl functionalization on nanotubes than that by $\mathrm{H}_{2} \mathrm{O}_{2} / \mathrm{HCl}$ treatment. The $\mathrm{Cu}$-coating on carbon nanotubes purified by both purification processes was complete, homogenous, and continuous. However, the $\mathrm{Cu}$-coating on carbon nanotubes purified by $\mathrm{H}_{2} \mathrm{O}_{2} / \mathrm{HCl}$ was oxidized more seriously than those on carbon nanotubes purified by $\mathrm{HNO}_{3}-\mathrm{NaOH}-\mathrm{HCl}$ treatment.
\end{abstract}

\section{Introduction}

Single-walled carbon nanotubes (SWCNTs) have nearly perfect bonding structures and no adjacent walls. Compared with multi-walled carbon nanotubes (MWCNTs), whose adjacent walls are easy to bridge to compensate for unsaturated carbon and cause defects, these defects are much less. SWCNTs are of excellent properties in ballistic electric and thermal conductivity, thermal stability and strength, and so forth, which enable them to be applicant in many fields such as nanoelectronic devices, structural, and functional composites.

When carbon nanotubes (CNTs) are used as reinforcement for copper matrix composite, the wettability and bonding strength of interfaces between CNTs and copper matrix are very poor; it is because that the surface tension of pure copper is $1270 \mathrm{mN} / \mathrm{m}$, far beyond the cut-off limit of surface tension $(100 \sim 200 \mathrm{mN} / \mathrm{m})$ to wet CNTs [1]. The physical and chemical properties of interfacial regions are discontinuous. It is difficult to achieve desirable macroeconomic performance of the CNTs reinforced copper matrix composite. At present, the most widely adopted method to solve the problem utilizes electroless plating process to prepare a layer of copper on the surface of CNTs as a transition layer. For instance, Daoush et al. [2] and Khaleghi et al. [3] successfully coated copper on the surface of CNTs by electroless plating and prepared copper matrix composite.

Nevertheless, commercial SWCNTs were synthesized with current techniques, such as chemical vapor deposition (CVD), high-pressure CO conversion (HiPCO), laser ablation and arc-discharge, and so forth [4-9] and usually contain several nanoimpurities including metal catalyst particles, amorphous carbon and flake graphite. Excellent properties of SWCNTs may be modified by these impurities, so that the full 
potential of SWCNTs is unable to be realized. Hence, it is essential to remove these impurities before SWCNTs are put into application.

Different purification methods have been developed and reported so far, which utilize one or morebasic techniques, like wet chemical oxidation with oxidants such as $\mathrm{H}_{2} \mathrm{O}_{2}$, nitric acid or $\mathrm{KMnO}_{4}$, gas phase thermal oxidation with $\mathrm{O}_{2}$, $\mathrm{CO}_{2}$, or $\mathrm{H}_{2} \mathrm{O}$ vapor at elevated temperature, microwave irradiation assisted acid digestion, microfiltration, and sizeexclusion chromatography [10-13]. Some aggressive processes usually damage SWCNTs severely and result in a low yield. There are still some problems in nondestructive processes such as microfiltration and size-exclusion chromatography, for example, long period, complex operation, and low yield. Other problems induced by the microwave process assisted acid digestion include large equipment investment, complex operation, and difficult control conditions.

Since the composition and the amount of impurities vary with synthesis methods of SWCNTs, the suitable purification methods are also different. The commercial grade SWCNTs synthesized by CVD were employed in this study. Thereupon, according to the composition and the amount of impurities in them, in comprehensive consideration of purification factors including cost, efficiency, operability and yield, purification methods with different oxidants were chosen to study. In fact, there are a few literatures describing these methods.

Fogden et al. [14] refluxed as-grown SWCNTs at $120^{\circ} \mathrm{C}$ either in concentrated $\mathrm{HNO}_{3}$ for $6 \mathrm{~h}$ or in a $3: 1$ mixture of concentrated sulphuric (98\%) and nitric acid (65\%) for $30 \mathrm{~min}$. They found that the mixed acid was much more oxidative and destroyed more SWCNTs. Similarly, Monthioux et al. [15] investigated a series of purification methods as follows: as-grown SWCNTs were refluxed with 2-3 M nitric acid for $45 \mathrm{~h}$, followed by $\mathrm{NaOH}$ washing, then purified in a $3: 1$ mixture of sulphuric $(98 \%)$ and nitric $(70 \%)$ acids at $70^{\circ} \mathrm{C}$ for 20-30 min, followed by $\mathrm{NaOH}$ washing, and finally oxidated with a $4: 1$ mixture of sulphuric acid (98\%) and hydrogen peroxide $(30 \%)$ at $70^{\circ} \mathrm{C}$ for $20-30 \mathrm{~min}$, followed by $\mathrm{NaOH}$ washing. They found that strong acid was harmful to the SWCNTS structure, and a slight temperature increase could result in significant SWCNTS degradation, while mild to mid strength acid treatments were able to remove impurities and damaged SWCNTs with minimal effect on the sample. In addition, Ma and Wang [16] refluxed as-grown SWCNTs at $100^{\circ} \mathrm{C}$ for $4 \mathrm{~h}$ either in $12 \mathrm{M} \mathrm{HCl}$ or in $14 \mathrm{M} \mathrm{HNO}_{3}$. They found that impurities including iron nanoparticles and non-CNT carbon removed from the as-grown SWCNTs by $14 \mathrm{M} \mathrm{HNO}_{3}$ were much more than those by $12 \mathrm{M} \mathrm{HCl}$. The nitric acid treatment in severe oxidation conditions, such as high concentration of nitric acid or long reaction time, could damage SWCNTs structure and dramatically decrease yield. Moreover, Mathur et al. [12] compared three purification methods of as-grown SWCNTs as follows: (a) treatment with $12 \mathrm{~N} \mathrm{HCl}$ for $12 \mathrm{~h}$ at room temperature, (b) reflux with $2.8 \mathrm{~N} \mathrm{HNO}_{3}$ for $6 \mathrm{~h}$, and (c) reflux with $6 \mathrm{NHCl}$ for $6 \mathrm{~h}$ and then with $2.8 \mathrm{~N} \mathrm{HNO}_{3}$ for $6 \mathrm{~h}$. They verified that great percentage of $\mathrm{Ni}$ and Co impurities could be removed from the as-grown SWCNTs by method (b) and (c). Wang et al. [17] heated the as-grown HiPco SWCNTs in an aqueous mixture of $\mathrm{H}_{2} \mathrm{O}_{2}$ and hydrochloric acid at $40-70^{\circ} \mathrm{C}$ for $4-8 \mathrm{~h}$ to remove carbon-coated iron catalyst nanoparticles. By lowering the $\mathrm{pH}$ to $\sim 1-3$, they found that the carbon-coated iron impurities were dissolved, leaving SWCNTs largely intact. This high selectivity was a result of the proximity effect of the ironcatalyzed Fenton chemistry. At $\mathrm{pH} \sim 1-3$, iron was dissolved upon exposure and releases ferrous ions. The ferrous ions quickly diffused into acid solution, so the unwanted catalytic effect of iron and iron hydroxide precipitation on digestion of SWCNTs by $\mathrm{H}_{2} \mathrm{O}_{2}$ was confined.

Raymundo-Piñero et al. [18] investigated the mechanism of chemical activation by solid $\mathrm{KOH}$ and $\mathrm{NaOH}$ in MWCNTs. And they demonstrated that the effect of $\mathrm{KOH}$ and $\mathrm{NaOH}$ on the structural organization of pristine MWCNTs was different. $\mathrm{NaOH}$ only attacked disordered carbons, whereas $\mathrm{KOH}$ was found to interact with all forms of carbons. In addition, Chungchamroenkit et al. [19] combined $\mathrm{NaOH}$ solution leaching and froth flotation to purify the SWCNTs synthesized by disproportionation of $\mathrm{CO}$ over a $\mathrm{Co}-\mathrm{Mo} / \mathrm{SiO}_{2}$ catalyst. And they found that most of the SWCNTs in sample were recovered without damaging the physical and chemical structures of SWCNTs.

Most of the procedures concentrated on the reduction of metal and nonnanotube carbon impurity, the chemical modification (functionalization) of SWCNTs and the structural changes of SWCNTs. The influence of different purification techniques on the subsequent specific application has not been reported.

Here we carried out a three-step-refluxing procedure with $\mathrm{HNO}_{3}-\mathrm{NaOH}-\mathrm{HCl}$ under mild conditions to purify SWCNTs sample. A previously reported purification process with $\mathrm{H}_{2} \mathrm{O}_{2} / \mathrm{HCl}$ was also repeated [17]. Then, the purified SWCNTs were coated with copper by the same electroless plating process. At the end, the effects of the two purification methods on the SWCNTs themselves and on electroless $\mathrm{Cu}-$ coating were determined by some modern analytical techniques and characteristic methods.

\section{Experimental}

SWCNTs synthesized by CVD were obtained from Chengdu Organic Chemicals co., LTD., Chinese Academy of Sciences. Analytical reagents such as hydrogen peroxide, nitric acid, sodium hydroxide, hydrochloric acid, and sodium dodecyl benzene sulfonate (SDBS) were commercially available. A CS-OY-CQ30 probe ultrasonic generator was employed to disperse SWCNTs before purification (Beijing Heng Odd Instrument Co., LTD.). A VOSHIN96-IIL bath ultrasonic generator was used to disperse SWCNTs during electroless plating (Wuxi Voshin Instrument Co., LTD.). Samples were filtered by $0.45 \mu \mathrm{m}$ millipore filters.

The original, purified, and electroless coated SWCNTs were evaluated by a field-emission scanning electron microscope (FESEM, Quanta 450) equipped with an energy dispersive spectroscopy analyzer (EDS, SUPRA 55 SAPPHIRE), a transmission electron microscope (TEM, HITACHIH7000FA), Chi600e electrochemical corrosion workshop, and an X-ray diffractometry (XRD, XD-2). Infrared transmittance spectra were obtained using a fourier transformed 
TABLE 1: Composition of copper electroless plating bath.

\begin{tabular}{lccccc}
\hline Chemical & $\mathrm{CuSO}_{4} \cdot 5 \mathrm{H}_{2} \mathrm{O}$ & $\mathrm{C}_{2} \mathrm{H}_{2} \mathrm{O}_{3}$ & EDTANa $_{2}$ & $\mathrm{NaKC}_{4} \mathrm{H}_{4} \mathrm{O}_{6} \cdot 4 \mathrm{H}_{2} \mathrm{O}$ & $2,2^{\prime}-\mathrm{Bipyridine}$ \\
\hline Concentration $/\left(\mathrm{mol} \cdot \mathrm{L}^{-1}\right)$ & 0.06 & 0.13 & 0.11 & 0.05 & $12\left(\mathrm{mg} \cdot \mathrm{L}^{-1}\right)$ \\
\hline
\end{tabular}

infrared spectroscopy (FT-IR, NEXUS). To evaluate the samples, thermogravimetric analysis was conducted in airflow with a heating rate of $10^{\circ} \mathrm{C} \mathrm{m^{-1 }}$ using a thermogravimetric analyzer (TGA, SDT Q600).

The detailed experimental procedures are presented as follows.

2.1. Ultrasonic Dispersion in SDBS Solution. A $0.025 \mathrm{w} / \mathrm{v} \%$ of initial SWCNTs sample was dispersed in a $0.35 \mathrm{w} / \mathrm{v} \%$ SDBS aqueous solution through ultrasonication for $30 \mathrm{~min}$. The ultrasonic dispersion employs a probe ultrasonic generator with a frequency of $35 \mathrm{kHz}$ and a power of $60 \mathrm{~W}$; and it stands for $5 \mathrm{~s}$ after ultrasonic treatment for $5 \mathrm{~s}$ in each $10 \mathrm{~s}$ cycle.

2.2. Purification with $\mathrm{HNO}_{3}-\mathrm{NaOH}-\mathrm{HCl}$. More mild purification conditions were chosen to prevent damage or loss of SWCNTs. The complete purification procedure had three steps. The first one was a nitric acid treatment to remove metal catalyst particles; the second one was a hydroxide treatment to exfoliate disordered carbon enclosing metal particles and then form insoluble metal hydroxides from the reaction with the metal particles upon their exposure; and the third one was a hydrochloric acid treatment to dissolve the metal hydroxides and to further remove the residual metal particles, sodium ions and amorphous carbon from the sample.

The detailed procedures are shown as follows. A $0.035 \mathrm{w} / \mathrm{v} \%$ of dispersed SWCNTs sample was refluxed in $6 \mathrm{M}$ nitric acid at $118^{\circ} \mathrm{C}$ for $5 \mathrm{~h}$, followed by deionized water washing. Then it was refluxed in $6 \mathrm{M}$ Sodium hydroxide at $118^{\circ} \mathrm{C}$ for $3 \mathrm{~h}$, followed by de-ionized water washing. Finally it was refluxed in $6 \mathrm{M}$ hydrochloric acid at $118^{\circ} \mathrm{C}$ for $3 \mathrm{~h}$, followed by deionized water washing. Finally, the sample was dried under vacuum for $3 \mathrm{~h}$ at $80^{\circ} \mathrm{C}$.

2.3. Purification with $\mathrm{H}_{2} \mathrm{O}_{2} / \mathrm{HCl}$ Mixture. For comparison, a previously reported purification process heating dispersed sample in an aqueous mixture of $30 \% \mathrm{H}_{2} \mathrm{O}_{2}$ and $1 \mathrm{~N}$ hydrochloric acid with an electromagnetic stirring at $60^{\circ} \mathrm{C}$ for $4 \mathrm{~h}$ was also carried out [17].

2.4. Electroless Copper Plating. A $0.025 \mathrm{w} / \mathrm{v} \%$ of purified SWCNTs sample was activated in an aqueous solution of $0.1 \mathrm{M} \mathrm{SnCl} / 2 / 0.1 \mathrm{M} \mathrm{HCl}$ through ultrasonic dispersion for $10 \mathrm{~min}$, followed by deionized water washing. Then it was sensitized in an aqueous solution of $0.014 \mathrm{M} \mathrm{PdCl}_{2} / 0.25 \mathrm{M} \mathrm{HCl}$ through ultrasonic dispersion for $8 \mathrm{~min}$, followed by deionized water washing. Then it was dispersed in an electroless copper plating bath (composition as shown in Table $1, \mathrm{pH}=$ 12.5) through ultrasonication at $45^{\circ} \mathrm{C}$ for $5 \mathrm{~min}$, followed by deionized water washing. Finally, the sample was dried under vacuum for $3 \mathrm{~h}$ at room temperature.

\section{Results and Discussion}

3.1. Characterization of Purified SWCNTs. TEM, XRD, and TGA were employed to characterize original and purified SWCNTs samples.

3.1.1. TEM Analysis. The samples for TEM were prepared by dropping the ethanol suspension of SWCNTs onto a grid which was left to air-dry. TEM images before and after purification (see Figure 1) show clearly the effectiveness of the two purification processes.

TEM image of initial sample (see Figure 1(a)) clearly shows entangled SWCNTs bundles in a mixture with metal nanoparticles (black dots), amorphous carbon encasing metal particles and free graphite particles flake graphite. The SWCNTs are typically $\sim 6 \mathrm{~nm}$ in diameter and 5 30 um in length. The size of metal particles ranges from ten to several ten $\mathrm{nm}$. There was no significant difference between the TEM micrographs of the sample purified by $\mathrm{HNO}_{3}-\mathrm{NaOH}-$ $\mathrm{HCl}$ treatment (see Figures $1(\mathrm{~b})$ and $1(\mathrm{c})$ ) and by $\mathrm{H}_{2} \mathrm{O}_{2} / \mathrm{HCl}$ treatment (see Figure 1(d)). Long SWCNTs with high structural quality were still observed. A comparison between Figures 1(c) and 1(d) (with a magnification of 150,000) reveals that both of the purification treatments can remove most of the metal particles and carbonaceous impurities without significant damage to SWNTs.

3.1.2. X-Ray Diffraction. Figure 2 shows that the XRD patterns of initial and purified SWCNTs samples over the range of angle shift values of $10^{\circ}$ through $90^{\circ}$. In the diffraction pattern $(2 \theta)$ of initial sample corresponding to Figure 2(a), two prominent peaks are observed at approximately 26.2 and 43.2, and two small peaks are observed at 56.3 and 80.0, respectively. The former two peaks are due to the $\left(\begin{array}{lll}0 & 0 & 2\end{array}\right)$ and (1 $\left.\begin{array}{ll}1 & 0\end{array}\right)$ planes of CNTs, while the latter two peaks correspond to iron metal. It confirms that iron was the main metal impurity present. By contrast, in the diffraction pattern $(2 \theta)$ of the samples purified by $\mathrm{HNO}_{3}-\mathrm{NaOH}-\mathrm{HCl}$ treatment and $\mathrm{H}_{2} \mathrm{O}_{2} / \mathrm{HCl}$ treatment corresponding to Figure 2(b) and (c), only the two peaks corresponding to the $\left(\begin{array}{lll}0 & 0 & 2\end{array}\right)$ and $\left(\begin{array}{lll}1 & 0 & 0\end{array}\right)$ planes of CNTs can be clearly determined, and the two peaks corresponding to iron metal are too faint to be observed. The XRD results clearly confirm that most iron impurities were removed by the two purification treatments.

3.1.3. TG Analysis. The TGA curves of initial and purified SWCNTs samples (see Figure 3) show that the weight loss upon heating from 20 to $900^{\circ} \mathrm{C}$. The final temperature $\left(900^{\circ} \mathrm{C}\right)$ was sufficient for complete burning of CNTs and carbonaceous impurities, leaving reddish brown iron oxide on the sample holder, namely $\mathrm{Fe}_{2} \mathrm{O}_{3}$. Therefore the residual weights (\%) after the heating process show the $\mathrm{Fe}_{2} \mathrm{O}_{3}$ contents. The TGA curves show that the corresponding ash 


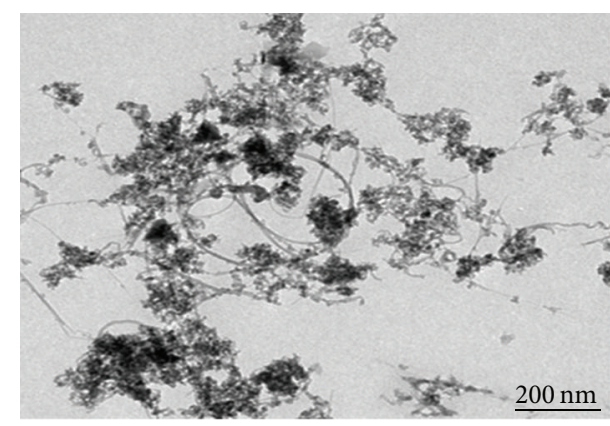

(a)

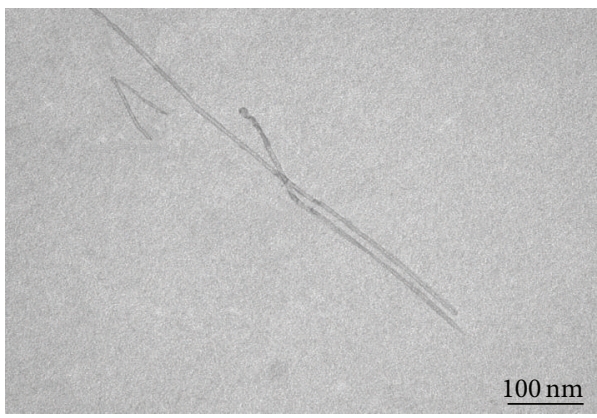

(c)

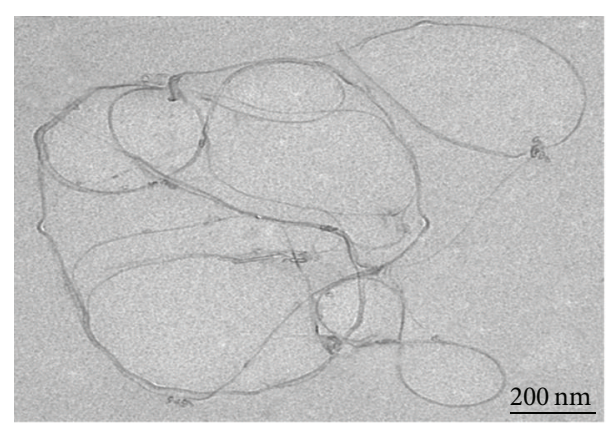

(b)

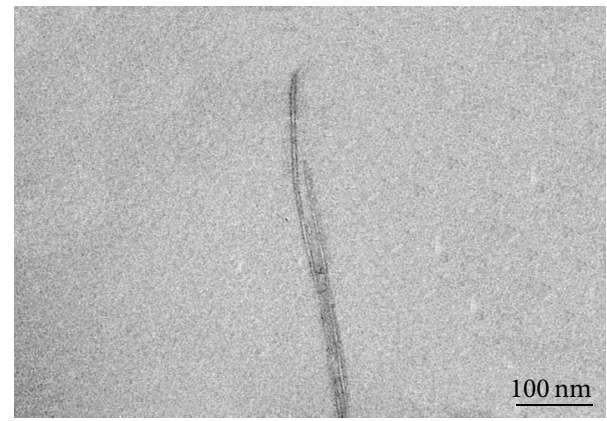

(d)

Figure 1: Representative TEM images of (a) initial SWCNTs sample and purified sample with (b, c) $\mathrm{HNO}_{3}-\mathrm{NaOH}-\mathrm{HCl}$ and $(\mathrm{d}) \mathrm{H}_{2} \mathrm{O}_{2} / \mathrm{HCl}$.

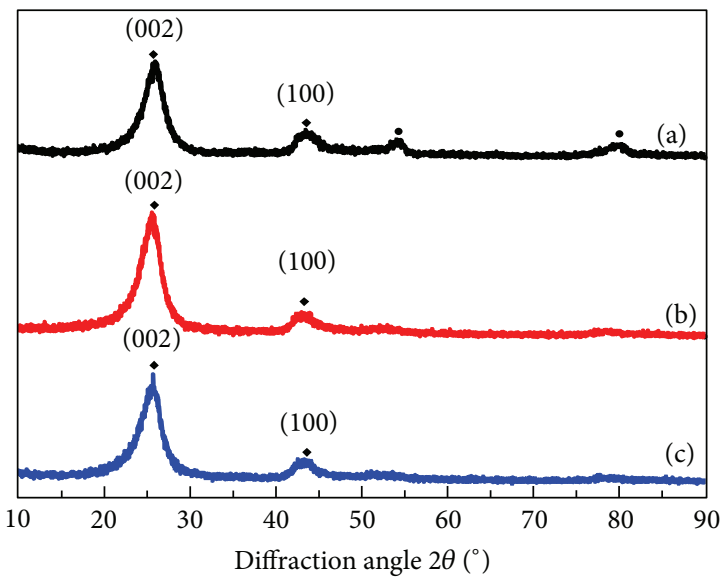

- CNTs

- $\mathrm{Fe}$

FIGURE 2: XRD patterns of (a) initial SWCNTs sample and purified sample with (b) $\mathrm{HNO}_{3}-\mathrm{NaOH}-\mathrm{HCl}$ and (c) $\mathrm{H}_{2} \mathrm{O}_{2} / \mathrm{HCl}$.

content $\left(\mathrm{Fe}_{2} \mathrm{O}_{3}\right)$ reduced from $13.3 \mathrm{wt} \%$ (initial sample) to $1.7 \mathrm{wt} \%\left(\mathrm{HNO}_{3}-\mathrm{NaOH}-\mathrm{HCl}\right.$ purified $)$, whereas it increased to $4.6 \mathrm{wt} \%$ after reacting with $\mathrm{H}_{2} \mathrm{O}_{2} / \mathrm{HCl}$. And the corresponding iron contents (weight \%) converted from $\mathrm{Fe}_{2} \mathrm{O}_{3}$ of initial sample, the samples purified by $\mathrm{HNO}_{3}-\mathrm{NaOH}-\mathrm{HCl}$ treatment and $\mathrm{H}_{2} \mathrm{O}_{2} / \mathrm{HCl}$ treatment are 9.7, 1.2, and $3.3 \mathrm{wt} \%$, respectively.

The curve of initial sample corresponding to Figure 3(a) shows a slight increase in weight at low temperatures due to

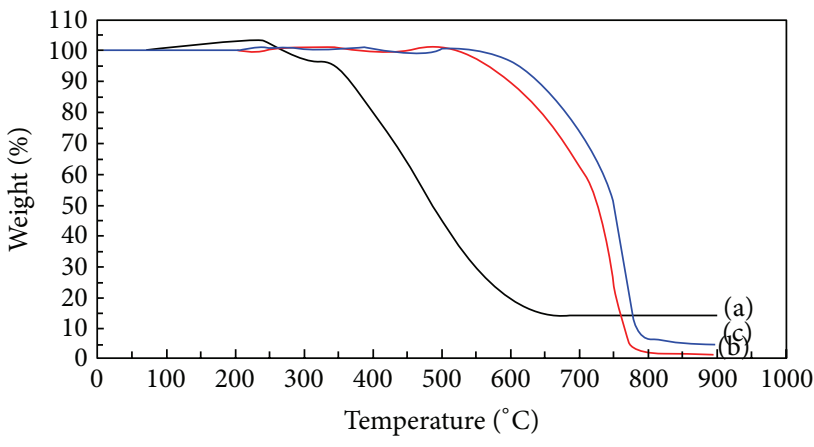

FIgURE 3: TGA curves of (a) initial SWCNTs sample and purified sample with (b) $\mathrm{HNO}_{3}-\mathrm{NaOH}-\mathrm{HCl}$ and (c) $\mathrm{H}_{2} \mathrm{O}_{2} / \mathrm{HCl}$.

oxidation of the Fe metal impurity [20], while the weight of the purified samples corresponding to Figure 3(b) and (c) did not increase at the same temperature. The TGA curve of initial sample begins to show weight loss at around $235^{\circ} \mathrm{C}$ and drops to $13.3 \mathrm{wt} \%$ below $620^{\circ} \mathrm{C}$. By contrast, purified samples show gentle degradation slopes above $620^{\circ} \mathrm{C}$, indicating their higher thermal stability. It is because that decomposition temperature of amorphous carbon in initial sample is low, and iron catalyst particles accelerate the oxidation rate of amorphous carbon as well as SWCNTs at low temperatures. The elimination of iron particles and carbonaceous impurities by the two purification treatments increased the degradation temperatures of SWCNTs. 
The TGA results clearly suggest that the two purification processes were effective in the removal of iron catalysts as well as carbonaceous impurities, as observed by TEM.

Furthermore, by comparison of degradation temperatures between Figure $3(\mathrm{~b})\left(543^{\circ} \mathrm{C} \sim 775^{\circ} \mathrm{C}\right)$ and (c) $\left(580^{\circ} \mathrm{C} \sim\right.$ $797^{\circ} \mathrm{C}$ ), it was found that the thermal stability of the sample purified by $\mathrm{H}_{2} \mathrm{O}_{2} / \mathrm{HCl}$ treatment was slightly higher than that purified by $\mathrm{HNO}_{3}-\mathrm{NaOH}-\mathrm{HCl}$ treatment. It shows that the change or damage to the SWNTs purified by $\mathrm{H}_{2} \mathrm{O}_{2} / \mathrm{HCl}$ was less than those purified by $\mathrm{HNO}_{3}-\mathrm{NaOH}-\mathrm{HCl}$.

Carbon atoms in SWCNTs skeleton are linked together by $\mathrm{sp}^{2}$ hybrid $\mathrm{C}=\mathrm{C}$ covalent bonds. Studies have shown that some $\mathrm{sp}^{2}$-C converted into $\mathrm{sp}^{3}-\mathrm{C}$ through refluxing SWCNTs in acid medium. Due to oxidizability of the metastable state $\mathrm{sp}^{3}$-C, defects could be caused in SWCNTs skeleton [21]. The stronger the acidity of refluxing solution is, the more susceptible to attacks the SWCNTs are [22]. In this study, the acidity of $\mathrm{HNO}_{3}$ solution $(\mathrm{Ph}=0)$ was stronger than $\mathrm{H}_{2} \mathrm{O}_{2} / \mathrm{HCl}$ mixture $(\mathrm{Ph}=3.5)$; thus, the change or damage to the SWCNTs purified by $\mathrm{H}_{2} \mathrm{O}_{2} / \mathrm{HCl}$ was less than those purified by $\mathrm{HNO}_{3}-\mathrm{NaOH}-\mathrm{HCl}$.

3.1.4. Infrared Spectroscopy Analysis. Figure 4 compares the IR spectra obtained from initial and purified SWCNTs samples. Infrared spectrum of initial sample corresponding to Figure 4(a) shows bands around 3435, 2927, and $1625 \mathrm{~cm}^{-1}$. The band at about $3435 \mathrm{~cm}^{-1}$ could be attributed to hydroxyl $(\nu \mathrm{OH})$ group, suggesting that initial SWCNTs were likely to entrap trace moisture; the peak at about $1625 \mathrm{~cm}^{-1}$ could be due to the stretching vibrations of water $\delta \mathrm{H}=\mathrm{O}$ or of aromatic $\mathrm{C}=\mathrm{C}$ corresponding to the $\mathrm{sp}^{2}-\mathrm{C}$ structure in SWCNTs skeleton; and the peak at about $2927 \mathrm{~cm}^{-1}$ corresponding to aliphatic $(\nu \mathrm{CH})$ group may be associated with debris from amorphous carbon in initial sample, as observed by TEM.

By contrast, the band corresponding to aliphatic group was absent in IR spectra of the samples purified by $\mathrm{HNO}_{3}$ $\mathrm{NaOH}-\mathrm{HCl}$ treatment and $\mathrm{H}_{2} \mathrm{O}_{2} / \mathrm{HCl}$ treatment corresponding to Figure 4(b) and (c), suggesting that amorphous carbon was not present. The results clearly confirm that most of the carbonaceous impurities were removed by the two purification treatments. Furthermore, both of the IR spectra from purified SWCNTs samples show bands around 3435, 1731,1667 and $1462 \mathrm{~cm}^{-1}$. The band at about $3435 \mathrm{~cm}^{-1}$ could also be due to hydroxyl group, suggesting moisture; the peaks at about 1731 and $1462 \mathrm{~cm}^{-1}$ could corroborate the presence of the carbonyl $(\nu \mathrm{C}=\mathrm{O})$ group, supporting carboxylfunctionalization on the surface of SWCNTs; and the peak at about $1667 \mathrm{~cm}^{-1}$ could be attributed to the stretching vibrations of $\mathrm{C}=\mathrm{O}$ in the carboxyl $(\nu \mathrm{COOH})$ group. The results suggest that the two purification processes were useful for SWCNTs functionalization. And it is positive for the electroless plating on the surface of SWCNTs.

Some oxygen-containing functional groups, such as hydroxyl groups and carboxyl groups, were introduced at defects or tips of SWCNTs skeleton through refluxing SWCNTs in acid medium. The degree of functionalization of SWCNTs depends upon the number of defects. The defects of the SWCNTs purified by $\mathrm{H}_{2} \mathrm{O}_{2} / \mathrm{HCl}$ were less than those

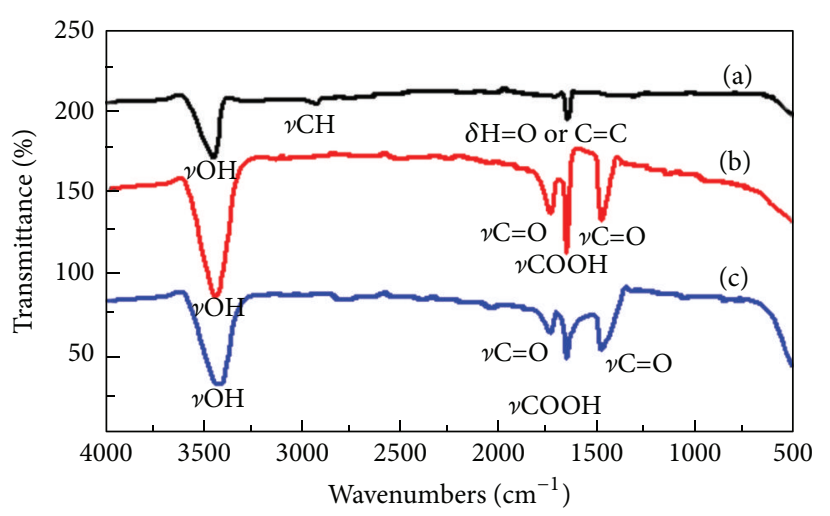

FIGURE 4: IR spectra of (a) initial SWCNTs sample and purified sample with (b) $\mathrm{HNO}_{3}-\mathrm{NaOH}-\mathrm{HCl}$ and (c) $\mathrm{H}_{2} \mathrm{O}_{2} / \mathrm{HCl}$.

purified by $\mathrm{HNO}_{3}-\mathrm{NaOH}-\mathrm{HCl}$, as described in previous section. Therefore, we could infer that the purification through $\mathrm{HNO}_{3}-\mathrm{NaOH}-\mathrm{HCl}$ treatment may be more effective for carboxyl functionalization on SWCNTs than that through $\mathrm{H}_{2} \mathrm{O}_{2} / \mathrm{HCl}$ treatment according to the FTIR analysis.

3.2. Characterization of Electroless Copper Coating. SEM, EDS, XRD, and TG-DTA were employed to characterizethe electroless copper coating on the surface of SWCNTs.

3.2.1. SEM and EDS Analyses. Some representative SEM micrographs of $\mathrm{Cu} / \mathrm{SWCNTs}$ samples purified by $\mathrm{HNO}_{3}$ $\mathrm{NaOH}-\mathrm{HCl}$ treatment and $\mathrm{H}_{2} \mathrm{O}_{2} / \mathrm{HCl}$ treatment are shown in Figures 5(a) and 5(b). A comparison between Figures 5(a) and 5 (b) indicates no significant differences in the morphology of $\mathrm{Cu}$-coatings which shows the fine-grain appearance of coating with a complete, homogenous and continuous distribution. The $\mathrm{Cu}$-deposited SWCNTs shown in Figure 5(a) are $110-210 \mathrm{~nm}$ in diameter, and those in Figure 5(b) are $140-360 \mathrm{~nm}$ in diameter. The diameter statistics of coated SWCNTs were collected about 30 diameters from each sample based on the measuring tool of SEM. These images indicate that the two purification treatments were all efficient to achieve $\mathrm{Cu}$ layer by an electroless deposition process on the surface of SWNTs.

Figures 6(a) and 6(b) show the EDX spectra for copper deposited SWCNTs corresponding to Figures 5(a) and 5(b). Both of the profiles show peaks for copper along with peaks for carbon and oxygen. Part of the observed oxygen might be the air trapped inside the SWCNTs or Cu-coating, the rest part might attribute to the oxidized coatings. Table 2 shows the tabulated element content values for $\mathrm{Cu} / \mathrm{SWCNTs}$ samples purified by $\mathrm{HNO}_{3}-\mathrm{NaOH}-\mathrm{HCl}$ and by $\mathrm{H}_{2} \mathrm{O}_{2} / \mathrm{HCl}$. The copper-to-carbon fraction of $\mathrm{Cu} / \mathrm{SWCNTs}$ purified by $\mathrm{HNO}_{3}-\mathrm{NaOH}-\mathrm{HCl}$ was $8.8 \%$ in atom, while that of $\mathrm{Cu} / \mathrm{SWCNTs}$ purified by $\mathrm{H}_{2} \mathrm{O}_{2} / \mathrm{HCl}$ was $10.8 \%$ in atom, indicating the latter $\mathrm{Cu}$-coating was thicker, as observed by SEM. And the oxygen-to-copper fraction of $\mathrm{Cu} / \mathrm{SWCNTs}$ purified by $\mathrm{HNO}_{3}-\mathrm{NaOH}-\mathrm{HCl}$ was $59.2 \%$ in atom, while that of $\mathrm{Cu} / \mathrm{SWCNTs}$ purified by $\mathrm{H}_{2} \mathrm{O}_{2} / \mathrm{HCl}$ was $145.8 \%$ in atom, 


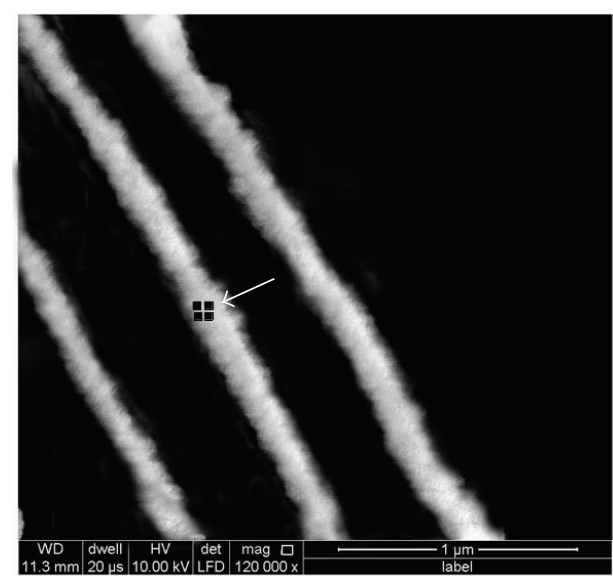

(a)

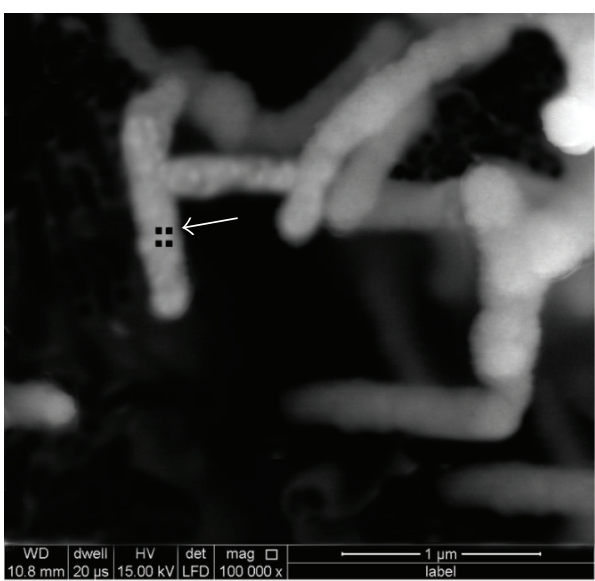

(b)

Figure 5: Representative SEM images of Cu/SWCNTs samples purified (a) by $\mathrm{HNO}_{3}-\mathrm{NaOH}-\mathrm{HCl}$ and (b) by $\mathrm{H}_{2} \mathrm{O}_{2} / \mathrm{HCl}_{\text {. }}$

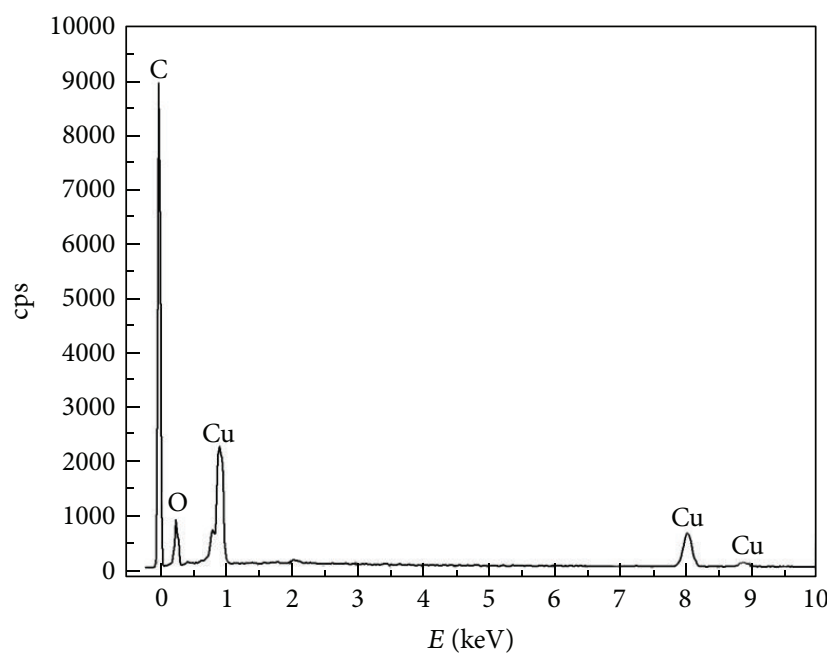

(a)

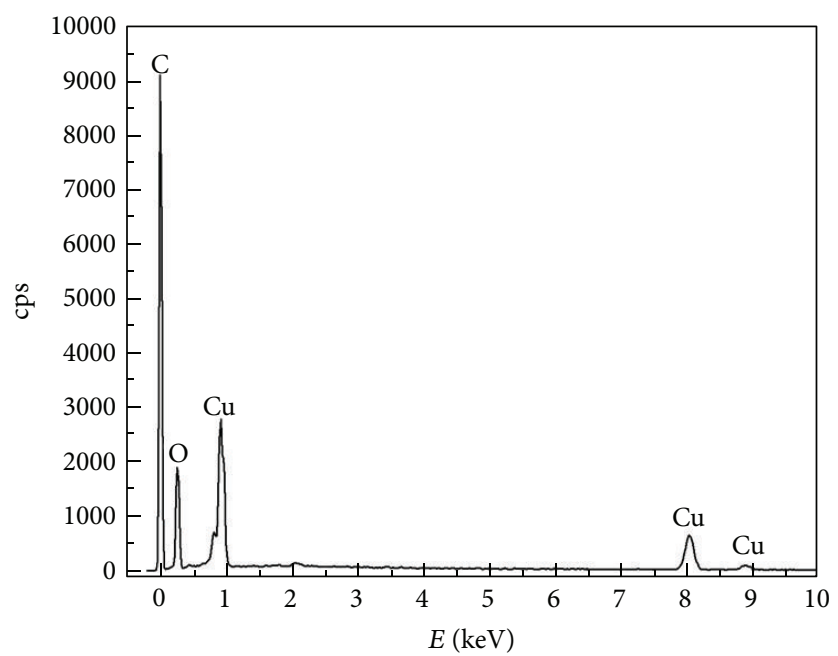

(b)

Figure 6: EDX spectra of $\mathrm{Cu} / \mathrm{SWCNTs}$ purified (a) by $\mathrm{HNO}_{3}-\mathrm{NaOH}-\mathrm{HCl}$ and (b) by $\mathrm{H}_{2} \mathrm{O}_{2} / \mathrm{HCl}$.

TABLE 2: Element contents of EDX spectra for Cu-deposited SWCNTs.

\begin{tabular}{lcccc}
\hline Sample & \multicolumn{2}{c}{$\begin{array}{c}\mathrm{Cu} / \mathrm{SWCNT} \text { purified by } \\
\mathrm{HNO}_{3} \text {-NaOH-HCl }\end{array}$} & \multicolumn{2}{c}{$\begin{array}{c}\mathrm{Cu} \text { /SWCNTs purified by } \\
\mathrm{H}_{2} \text { / }\end{array}$} \\
\hline Element & wt.\% & at.\% & wt.\% & at.\% \\
\hline $\mathrm{C}$ & 52.52 & 80.86 & 56.08 & 78.98 \\
$\mathrm{O}$ & 6.16 & 7.12 & 11.80 & 12.47 \\
$\mathrm{Cu}$ & 41.32 & 12.02 & 32.12 & 8.55 \\
\hline
\end{tabular}

indicating that the latter $\mathrm{Cu}$-coating was oxidized more seriously.

$\mathrm{H}_{2} \mathrm{O}_{2}$ is unstable under heat and easy to discompose to $\mathrm{H}_{2} \mathrm{O}$ and $\mathrm{O}_{2}$. The reactions are as follows:

$$
\mathrm{H}_{2} \mathrm{O}_{2} \stackrel{\Delta}{\rightarrow} \mathrm{H}_{2} \mathrm{O}+\frac{1}{2} \mathrm{O}_{2} \uparrow
$$

Some moisture and oxygen might be trapped inside the SWCNTs. They could cause the oxidation of $\mathrm{Cu}$-coating. The density of copper is $8.96 \mathrm{~g} / \mathrm{cm}^{3}$, and that of copper oxides is $6.0 \sim 6.3 \mathrm{~g} / \mathrm{cm}^{3}$. Cu-coating produced a certain volume expansion after oxidation. The SWCNTs treated with $\mathrm{H}_{2} \mathrm{O}_{2} / \mathrm{HCl}$ oxidized more seriously and so they possess thicker $\mathrm{Cu}$ coating than that treated with $\mathrm{HNO}_{3}-\mathrm{NaOH}-\mathrm{HCl}$.

3.2.2. X-Ray Diffraction. The XRD patterns of $\mathrm{Cu} / \mathrm{SWCNTs}$ samples purified by $\mathrm{HNO}_{3}-\mathrm{NaOH}-\mathrm{HCl}$ treatment and $\mathrm{H}_{2} \mathrm{O}_{2} / \mathrm{HCl}$ treatment over the range of angle shift values of $20^{\circ}$ through $80^{\circ}$ are shown in Figure 7 . In the diffraction pattern $(2 \theta)$ of $\mathrm{Cu} / \mathrm{SWCNT}$ purified sample by $\mathrm{HNO}_{3}$ $\mathrm{NaOH}-\mathrm{HCl}$ corresponding to Figure $7(\mathrm{a})$, five peaks are observed at approximately 32.6, 41.2, 56.3, 62.21, and 73.26, respectively. The peaks at $41.2,56.3$ and 73.26 were assigned to the (111), (111), and (311) planes of the fcc phase of copper, 


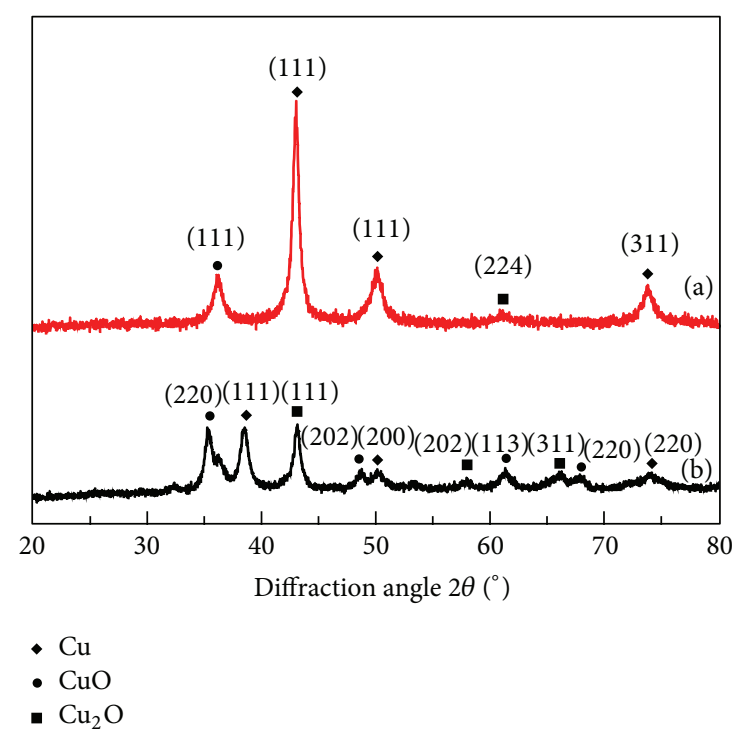

FIgURE 7: XRD patterns of $\mathrm{Cu} / \mathrm{SWCNTs}$ purified (a) by $\mathrm{HNO}_{3}$ $\mathrm{NaOH}-\mathrm{HCl}$ and (b) by $\mathrm{H}_{2} \mathrm{O}_{2} / \mathrm{HCl}$.

and the rest two peaks at 32.6 and 62.21 correspond to $\mathrm{CuO}$ and $\mathrm{Cu}_{2} \mathrm{O}$, respectively. By contrast, in the diffraction pattern of the $\mathrm{Cu} / \mathrm{SWCNTs}$ purified sample by $\mathrm{H}_{2} \mathrm{O}_{2} / \mathrm{HCl}$ corresponding to Figure $7(\mathrm{~b})$, ten peaks are observed at approximately $34.62,38.6,41.7,47.6,49.5,57.2,62.3,67.8,69.6$, and 73.2 , respectively. The three peaks at $38.6,49.5$, and 73.2 correspond to the (1 1 1 ), (2 00 ), and (2 20$)$ planes of the fcc phase of copper, and the rest peaks are due to $\mathrm{CuO}$ or $\mathrm{Cu}_{2} \mathrm{O}$.

By comparing the diffraction peaks of purified SWCNTs samples in Figure 2, it was confirmed that layers of crystalline copper were newly introduced on surfaces of SWCNTs by electroless deposition. Furthermore, on comparison of the XRD results between Figure 7(a) and (b), it found that the $\mathrm{Cu}$-coating on the SWCNTs purified by $\mathrm{HNO}_{3}-\mathrm{NaOH}-\mathrm{HCl}$ were more compact than those on SWCNTs purified by $\mathrm{H}_{2} \mathrm{O}_{2} / \mathrm{HCl}$, because they were composed of (111) and (311) fcc planes, whose atomic arrangements were more intensive than those in the $\mathrm{Cu}$-coating on SWCNTs purified by $\mathrm{H}_{2} \mathrm{O}_{2} / \mathrm{HCl}$. In addition, the $\mathrm{XRD}$ results also clearly indicate that the $\mathrm{Cu}$ coating on SWCNTs purified by $\mathrm{H}_{2} \mathrm{O}_{2} / \mathrm{HCl}$ were oxidized more seriously, which was consistent with the above EDS results.

3.2.3. TG-DTA. Figure 8 shows the TGA and DTA curves of SWCNTs and $\mathrm{Cu} / \mathrm{SWCNTs}$ samples purified by $\mathrm{HNO}_{3}$ $\mathrm{NaOH}-\mathrm{HCl}$ and by $\mathrm{H}_{2} \mathrm{O}_{2} / \mathrm{HCl}$ at temperature from 20 to $900^{\circ} \mathrm{C}$. The final temperature $\left(900^{\circ} \mathrm{C}\right)$ was sufficient for complete burning of SWCNTs, leaving black $\mathrm{CuO}$ on the sample holder. Therefore the residual weights (\%) after the heating process show the $\mathrm{CuO}$ contents. The TGA curves in Figure 8(a) show that the corresponding ash content $(\mathrm{CuO})$ increased from $1.7 \mathrm{wt} \%\left(\mathrm{HNO}_{3}-\mathrm{NaOH}-\mathrm{HCl}\right.$ purified sample) to $47.2 \mathrm{wt} \%\left(\mathrm{Cu} / \mathrm{SWCNTs}\right.$ purified by $\mathrm{HNO}_{3}-\mathrm{NaOH}-$ $\mathrm{HCl})$, whereas it increased from $4.6 \mathrm{wt} \%\left(\mathrm{H}_{2} \mathrm{O}_{2} / \mathrm{HCl}\right.$ purified sample) to $40.5 \mathrm{wt} \%\left(\mathrm{Cu} / \mathrm{SWCNTs}\right.$ purified by $\left.\mathrm{H}_{2} \mathrm{O}_{2} / \mathrm{HCl}\right)$.
And the corresponding copper contents (weight \%) converted from $\mathrm{CuO}$ of $\mathrm{Cu} / \mathrm{SWCNTs}$ samples purified by $\mathrm{HNO}_{3}$ $\mathrm{NaOH}-\mathrm{HCl}$ and by $\mathrm{H}_{2} \mathrm{O}_{2} / \mathrm{HCl}$ are 41.7 and $35.3 \mathrm{wt} \%$, respectively.

The TGA curve (A) in Figure 8(a) corresponding to the $\mathrm{Cu} / \mathrm{SWCNTs}$ purified by $\mathrm{HNO}_{3}-\mathrm{NaOH}-\mathrm{HCl}$ shows a slight increase in weight at low temperatures. It coincides with two exothermic peaks of DTA curve (A) in Figure 8(b) at approximately $150^{\circ} \mathrm{C}$ and $290^{\circ} \mathrm{C}$, respectively.

The first exothermic peak corresponds to the oxide of metallic copper into $\mathrm{Cu}_{2} \mathrm{O}$, and the second peak corresponds to the oxidization of $\mathrm{Cu}_{2} \mathrm{O}$ into $\mathrm{CuO}$, simultaneously to the oxidization of metallic copper into $\mathrm{Cu}_{2} \mathrm{O}$. The reactions are as follows [23]:

$$
\begin{gathered}
2 \mathrm{Cu}+\frac{1}{2} \mathrm{O}_{2} \longrightarrow \mathrm{Cu}_{2} \mathrm{O} \quad \Delta \mathrm{H}_{f}=-172.4 \mathrm{~kJ} / \mathrm{mol} \\
\mathrm{Cu}+\frac{1}{2} \mathrm{O}_{2} \longrightarrow \mathrm{CuO} \quad \Delta \mathrm{H}_{f}=-160.0 \mathrm{~kJ} / \mathrm{mol} \\
\frac{1}{2} \mathrm{Cu}_{2} \mathrm{O}+\frac{1}{4} \mathrm{O}_{2} \longrightarrow \mathrm{CuO} \quad \Delta \mathrm{H}_{f}=-73.8 \mathrm{~kJ} / \mathrm{mol}
\end{gathered}
$$

While the weight of $\mathrm{Cu} / \mathrm{SWCNTs}$ purified by $\mathrm{H}_{2} \mathrm{O}_{2} / \mathrm{HCl}$ has no significant increase (see TGA curve (B) in Figure 8(a)) at the same temperature and the two homologous peaks of DTA curve (B) in Figure 8(b) was much weaker at approximately $155^{\circ} \mathrm{C}$ and $320^{\circ} \mathrm{C}$, respectively, it indicates that the latter $\mathrm{Cu}-$ coating was oxidized more seriously before TG-DTA testing, which was consistent with the EDS and XRD results.

The DTA curves (C and D) in Figure 8(b) corresponding to purified SWCNTs show exothermic peaks above $650^{\circ} \mathrm{C}$ was due to the SWCNTs oxidization, because it was accompanied by a sharp weight decrease in Figure 8(a). However, the degradation temperatures of $\mathrm{Cu} / \mathrm{SWCNTs}$ samples were greatly reduced to $550^{\circ} \mathrm{C}$ (see DTA curve (A) in Figure 8(b)) and $600^{\circ} \mathrm{C}$ (see DTA curve (B) in Figure 8(b)), showing that the thermal stability of $\mathrm{Cu} / \mathrm{SWCNTs}$ samples decreased. It is due the catalytic effect of copper on the oxidization of SWCNTs.

\subsubsection{Electric and Thermal Conductivity. Cu/SWCNTs} papers $(25 \mathrm{~mm} \times 8 \mathrm{~mm} \times 0.225 \mathrm{~mm})$ have been prepared through vacuum filtration, as black sheets shown in Figure 9. Both ends of each black sheet were clamped by two pieces of copper to be fixed on sheet glass. As a result of electrochemical corrosion workshop correction, curves of relationship between current and voltage (see Figure 10) were established to convert the original data value into resistivity. The resistivity of $\mathrm{Cu} / \mathrm{SWCNT}$ papers purified by $\mathrm{HNO}_{3}-\mathrm{NaOH}-$ $\mathrm{HCl}$ was $0.08111 \Omega \cdot \mathrm{mm}$, and that of $\mathrm{Cu} / \mathrm{SWCNTs}$ papers purified by $\mathrm{H}_{2} \mathrm{O}_{2} / \mathrm{HCl}$ was $0.17805 \Omega \cdot \mathrm{mm}$. The results were affected by the dispersion, dispersant and the thickness of the sheets $[24,25]$. Both of the papers were prepared and detected under the same conditions. It is because the SWCNTs treated with $\mathrm{H}_{2} \mathrm{O}_{2} / \mathrm{HCl}$ oxidized more seriously and their $\mathrm{Cu}$-coating have lower electric conductivity than that treated with $\mathrm{HNO}_{3}-\mathrm{NaOH}-\mathrm{HCl}$.

The thermal conductivity of bulk $\mathrm{Cu}$ is $401 \mathrm{~W} \cdot \mathrm{m}^{-1} \cdot \mathrm{K}^{-1}$ order in the literature, that of bulk $\mathrm{CuO}$ is $17 \mathrm{~W} \cdot \mathrm{m}^{-1} \cdot \mathrm{K}^{-1}$. 


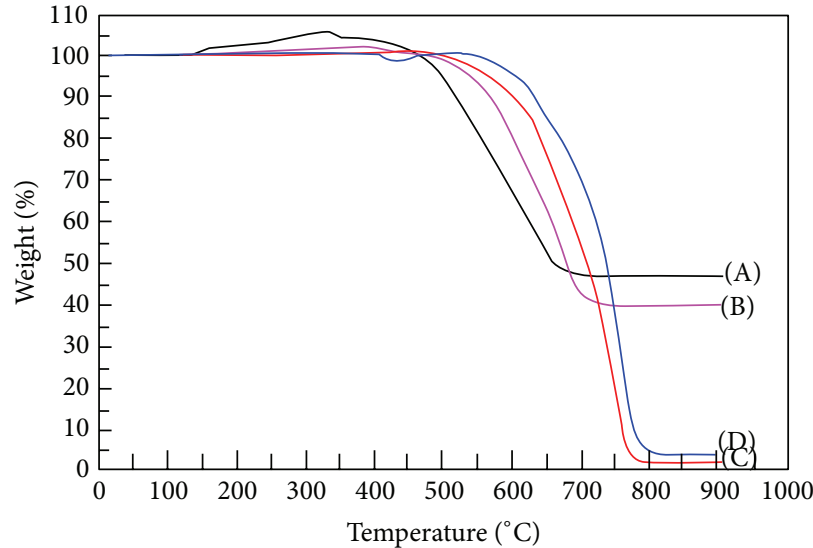

(a)

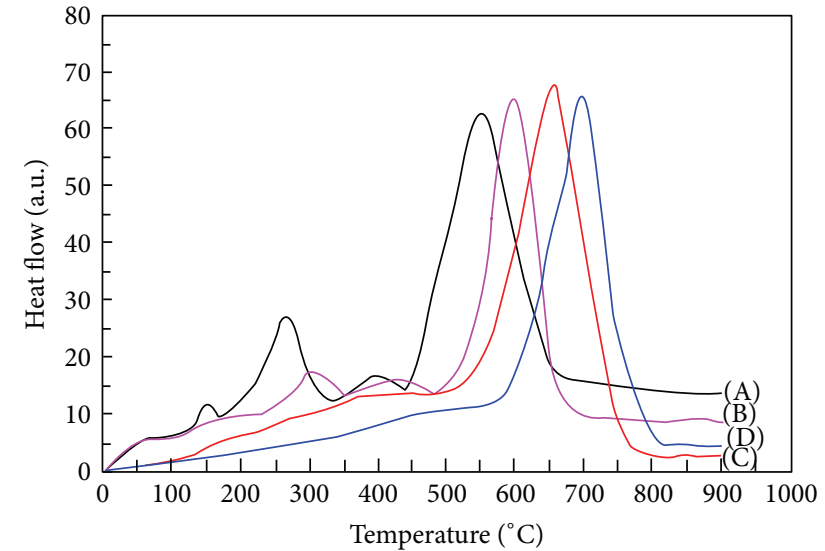

(b)

Figure 8: (a) TGA and (b) DTA curves of $\mathrm{Cu} / \mathrm{SWCNTs}$ purified (A) by $\mathrm{HNO}_{3}-\mathrm{NaOH}-\mathrm{HCl}$ and (B) by $\mathrm{H}_{2} \mathrm{O}_{2} / \mathrm{HCl}$, SWCNTs purified (C) by $\mathrm{HNO}_{3}-\mathrm{NaOH}-\mathrm{HCl}$ and (D) by $\mathrm{H}_{2} \mathrm{O}_{2} / \mathrm{HCl}$.

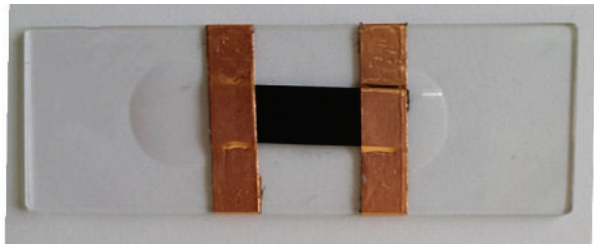

(a)

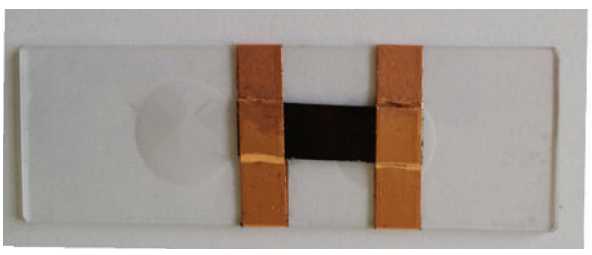

(b)

FIgURE 9: Cu/SWCNTs papers (black sheets) purified (a) by $\mathrm{HNO}_{3}-\mathrm{NaOH}-\mathrm{HCl}$ and (b) by $\mathrm{H}_{2} \mathrm{O}_{2} / \mathrm{HCl}$.

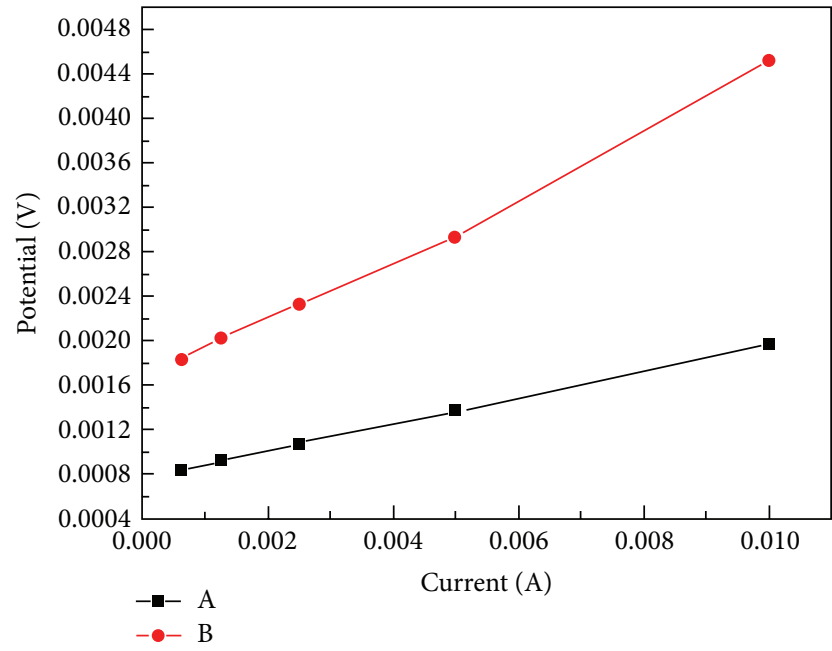

Figure 10: $I-V$ curves of $\mathrm{Cu} / \mathrm{SWCNTs}$ papers purified (A) by $\mathrm{HNO}_{3}-\mathrm{NaOH}-\mathrm{HCl}$ and (B) by $\mathrm{H}_{2} \mathrm{O}_{2} / \mathrm{HCl}$.

The intrinsic thermal conductivity of $\mathrm{CuO}$ film was lower than $4 \mathrm{~W} \cdot \mathrm{m}^{-1} \cdot \mathrm{K}^{-1}$. Thus oxidation would cause the reduced thermal conductivity of $\mathrm{Cu}$-coating.

\section{Conclusions}

In this paper, a three-step-refluxing procedure for the purification of SWCNTs was described. SWCNTs samples synthesized by CVD were treated in nitric acid, hydroxide, and hydrochloric acid successively. For comparison, a previously reported purification process heating SWCNTs sample in $\mathrm{H}_{2} \mathrm{O}_{2} / \mathrm{HCl}$ mixture was also carried out. After purifying using the two different methods, SWCNTs were all coated with copper by the same electroless plating process.

The results of TEM, XRD, TGA, and IR spectra clearly confirm that both of the purification treatments can remove most of the iron catalyst particles and carbonaceous impurities without significant damage to SWNTs, and the thermal stability of the sample purified by $\mathrm{H}_{2} \mathrm{O}_{2} / \mathrm{HCl}$ treatment was slightly higher than that purified by $\mathrm{HNO}_{3}-\mathrm{NaOH}-\mathrm{HCl}$ treatment. However, the purification by $\mathrm{HNO}_{3}-\mathrm{NaOH}-\mathrm{HCl}$ treatment was more effective for carboxyl functionalization on SWCNTs than that by $\mathrm{H}_{2} \mathrm{O}_{2} / \mathrm{HCl}$ treatment.

The results of SEM, EDS, XRD and TG-DTA reveal no significant differences in the morphology of $\mathrm{Cu}$-coating which shows the fine-grain appearance of coating with a complete, homogenous and continuous distribution. Nevertheless, the $\mathrm{Cu}$-coating on the SWCNTs purified by $\mathrm{HNO}_{3}$ $\mathrm{NaOH}-\mathrm{HCl}$ was more compact, while the $\mathrm{Cu}$-coating on SWCNTs purified by $\mathrm{H}_{2} \mathrm{O}_{2} / \mathrm{HCl}$ was oxidized more seriously. 
When SWCNTs are used as reinforcement for copper matrix composite, the presence of copper oxide in $\mathrm{Cu}$-coating on SWCNTs would weaken the performance of coating in electric and thermal conductivity and decrease the bonding strength of interfaces between SWCNTs and copper matrix. Therefore, the three-step-refluxing purification pretreatment was more suitable for the application of SWCNTs in copper matrix composite to achieve desirable macroeconomic performance of composite.

\section{Conflict of Interests}

The authors declare that there is no conflict of interests regarding the publication of this paper.

\section{Acknowledgments}

The authors thank the financial support from the National Natural Science Foundation of China (Grant no. 5120514) and Hubei Provincial Key Laboratory of Green Materials for Light Industry (Grant no. 20132-15).

\section{References}

[1] E. Dujardin, T. W. Ebbesen, H. Hiura, and K. Tanigaki, "Capillarity and wetting of carbon nanotubes," Science, vol. 265, no. 5180, pp. 1850-1852, 1994.

[2] W. M. Daoush, B. K. Lim, C. B. Mo, D. H. Nam, and S. H. Hong, "Electrical and mechanical properties of carbon nanotube reinforced copper nanocomposites fabricated by electroless deposition process," Materials Science and Engineering A, vol. 513-514, pp. 247-253, 2009.

[3] E. Khaleghi, M. Torikachvili, M. A. Meyers, and E. A. Olevsky, "Magnetic enhancement of thermal conductivity in coppercarbon nanotube composites produced by electroless plating, freeze drying, and spark plasma sintering," Materials Letters, vol. 79, pp. 256-258, 2012.

[4] D. Y. Kim, H. Sugime, K. Hasegawa, T. Osawa, and S. Noda, "Sub-millimeter-long carbon nanotubes repeatedly grown on and separated from ceramic beads in a single fluidized bed reactor," Carbon, vol. 49, no. 6, pp. 1972-1979, 2011.

[5] D. Y. Kim, H. Sugime, K. Hasegawa, T. Osawa, and S. Noda, "Fluidized-bed synthesis of sub-millimeter-long single walled carbon nanotube arrays," Carbon, vol. 50, no. 4, pp. 1538-1545, 2012.

[6] E. C. Neyts, K. Ostrikov, Z. J. Han, S. Kumar, A. C. T. Van Duin, and A. Bogaerts, "Defect healing and enhanced nucleation of carbon nanotubes by low-energy ion bombardment," Physical Review Letters, vol. 110, no. 6, Article ID 065501, 2013.

[7] M. Meyyappan, "Catalyzed chemical vapor deposition of onedimensional nanostructures and their applications," Progress in Crystal Growth and Characterization of Materials, vol. 55, no. 1-2, pp. 1-21, 2009.

[8] K. Moothi, S. E. Iyuke, M. Meyyappan, and R. Falcon, "Coal as a carbon source for carbon nanotube synthesis," Carbon, vol. 50, no. 8, pp. 2679-2690, 2012.

[9] Y. Li, H. Wang, G. Wang, and J. Gao, "Synthesis of single-walled carbon nanotubes from heavy oil residue," Chemical Engineering Journal, vol. 211-212, pp. 255-259, 2012.

[10] K. MacKenzie, O. Dunens, and A. T. Harris, "A review of carbon nanotube purification by microwave assisted acid digestion,"
Separation and Purification Technology, vol. 66, no. 2, pp. 209222, 2009.

[11] B. Vigolo, C. Hérold, J.-F. Marêché et al., "A comprehensive scenario for commonly used purification procedures of arcdischarge as-produced single-walled carbon nanotubes," Carbon, vol. 48, no. 4, pp. 949-963, 2010.

[12] R. B. Mathur, S. Seth, C. Lal et al., "Co-synthesis, purification and characterization of single- and multi-walled carbon nanotubes using the electric arc method," Carbon, vol. 45, no. 1, pp. 132-140, 2007.

[13] C. G. Salzmann, S. A. Llewellyn, G. Tobias, M. A. H. Ward, Y. Huh, and M. L. H. Green, "The role of carboxylated carbonaceous fragments in the functionalization and spectroscopy of a single-walled carbon-nanotube material," Advanced Materials, vol. 19, no. 6, pp. 883-887, 2007.

[14] S. Fogden, R. Verdejo, B. Cottam, and M. Shaffer, "Purification of single walled carbon nanotubes: the problem with oxidation debris," Chemical Physics Letters, vol. 460, no. 1-3, pp. 162-167, 2008.

[15] M. Monthioux, B. W. Smith, B. Burteaux, A. Claye, J. E. Fischer, and D. E. Luzzi, "Sensitivity of single-wall carbon nanotubes to chemical processing: an electron microscopy investigation," Carbon, vol. 39, no. 8, pp. 1251-1272, 2001.

[16] J. Ma and J. N. Wang, "Purification of single-walled carbon nanotubes by a highly efficient and nondestructive approach," Chemistry of Materials, vol. 20, no. 9, pp. 2895-2902, 2008.

[17] Y. Wang, H. Shan, R. H. Hauge, M. Pasquali, and R. E. Smalley, "A highly selective, one-pot purification method for singlewalled carbon nanotubes," The Journal of Physical Chemistry B, vol. 111, no. 6, pp. 1249-1252, 2007.

[18] E. Raymundo-Piñero, P. Azaïs, T. Cacciaguerra, D. CazorlaAmorós, A. Linares-Solano, and F. Béguin, " $\mathrm{KOH}$ and $\mathrm{NaOH}$ activation mechanisms of multiwalled carbon nanotubes with different structural organisation," Carbon, vol. 43, no. 4, pp. 786-795, 2005.

[19] P. Chungchamroenkit, S. Chavadej, U. Yanatatsaneejit, and B. Kitiyanan, "Residue catalyst support removal and purification of carbon nanotubes by $\mathrm{NaOH}$ leaching and froth flotation," Separation and Purification Technology, vol. 60, no. 2, pp. 206214, 2008.

[20] A. C. Dillon, T. Gennett, K. M. Jones, J. L. Alleman, P. A. Parilla, and M. J. Heben, "A simple and complete purification of singlewalled carbon nanotube materials," Advanced Materials, vol. 11, no. 16, pp. 1354-1358, 1999.

[21] W. Zhou, S. Sasaki, and A. Kawasaki, "Effective control of nanodefects in multiwalled carbon nanotubes by acid treatment," Carbon, vol. 78, pp. 121-129, 2014.

[22] Y.-T. Shieh, G.-L. Liu, H.-H. Wu, and C.-C. Lee, "Effects of polarity and $\mathrm{pH}$ on the solubility of acid-treated carbon nanotubes in different media," Carbon, vol. 45, no. 9, pp. 1880-1890, 2007.

[23] D. R. Lide, CRC Handbook of Chemistry and Physics: A ReadyReference Book of Chemical and Physical Data. 2000, Taylor \& Francis, 2006.

[24] P. Singjai, S. Changsarn, and S. Thongtem, "Electrical resistivity of bulk multi-walled carbon nanotubes synthesized by an infusion chemical vapor deposition method," Materials Science and Engineering A, vol. 443, no. 1-2, pp. 42-46, 2007.

[25] H. Xing, L. Sun, G. Song, J. Gou, and Y. W. Hao, "Surface coating of carbon nanofibers/nanotubes by electrodeposition for multifunctionalization," Nanotechnology, vol. 19, no. 2, Article ID 025704, 2008. 

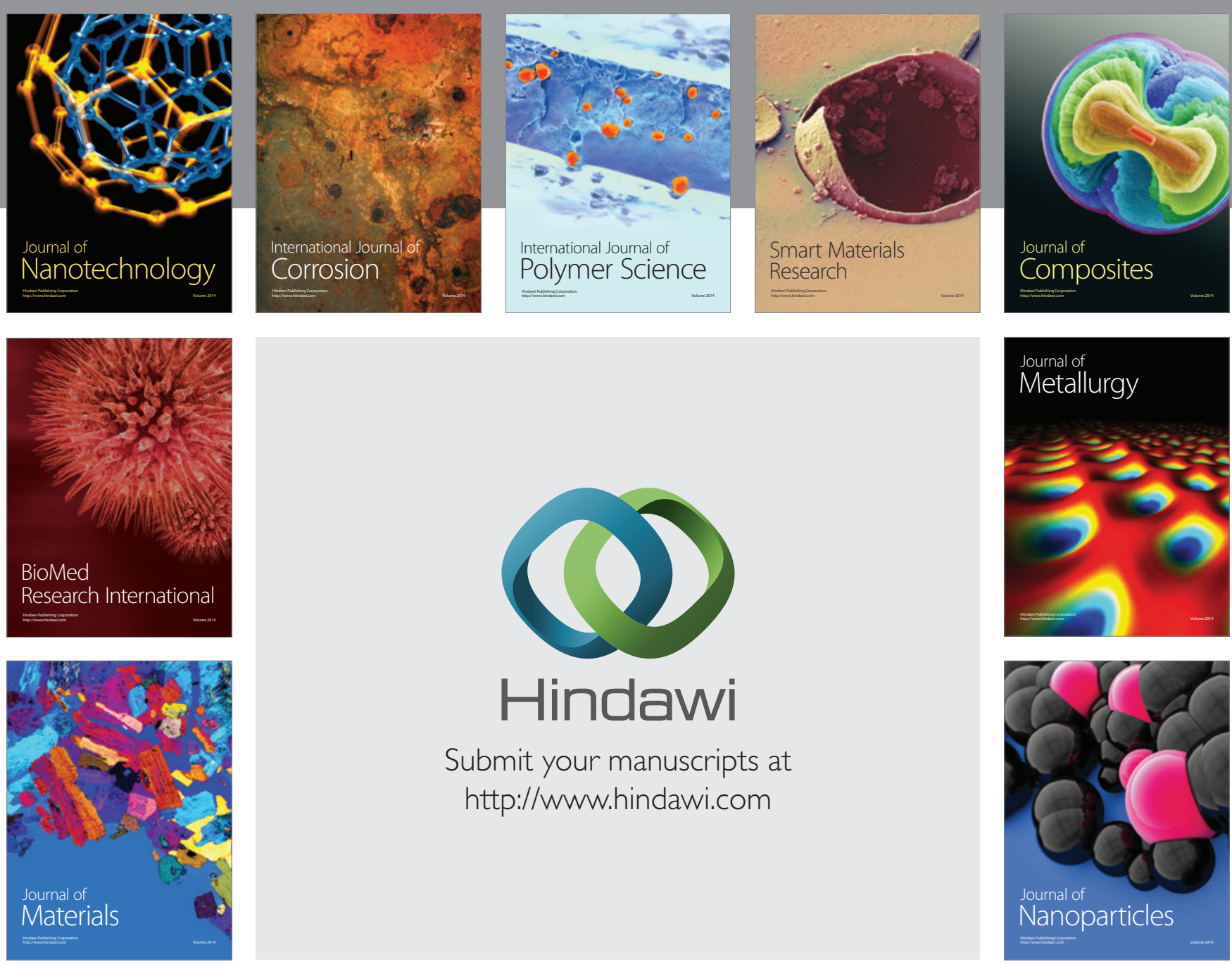

Submit your manuscripts at http://www.hindawi.com
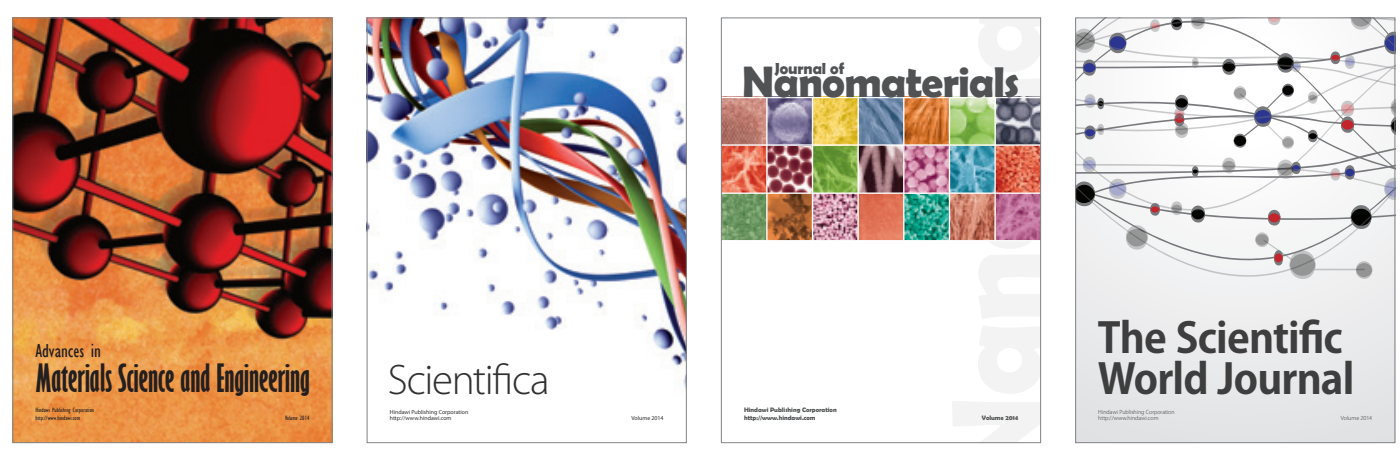

\section{The Scientific World Journal}
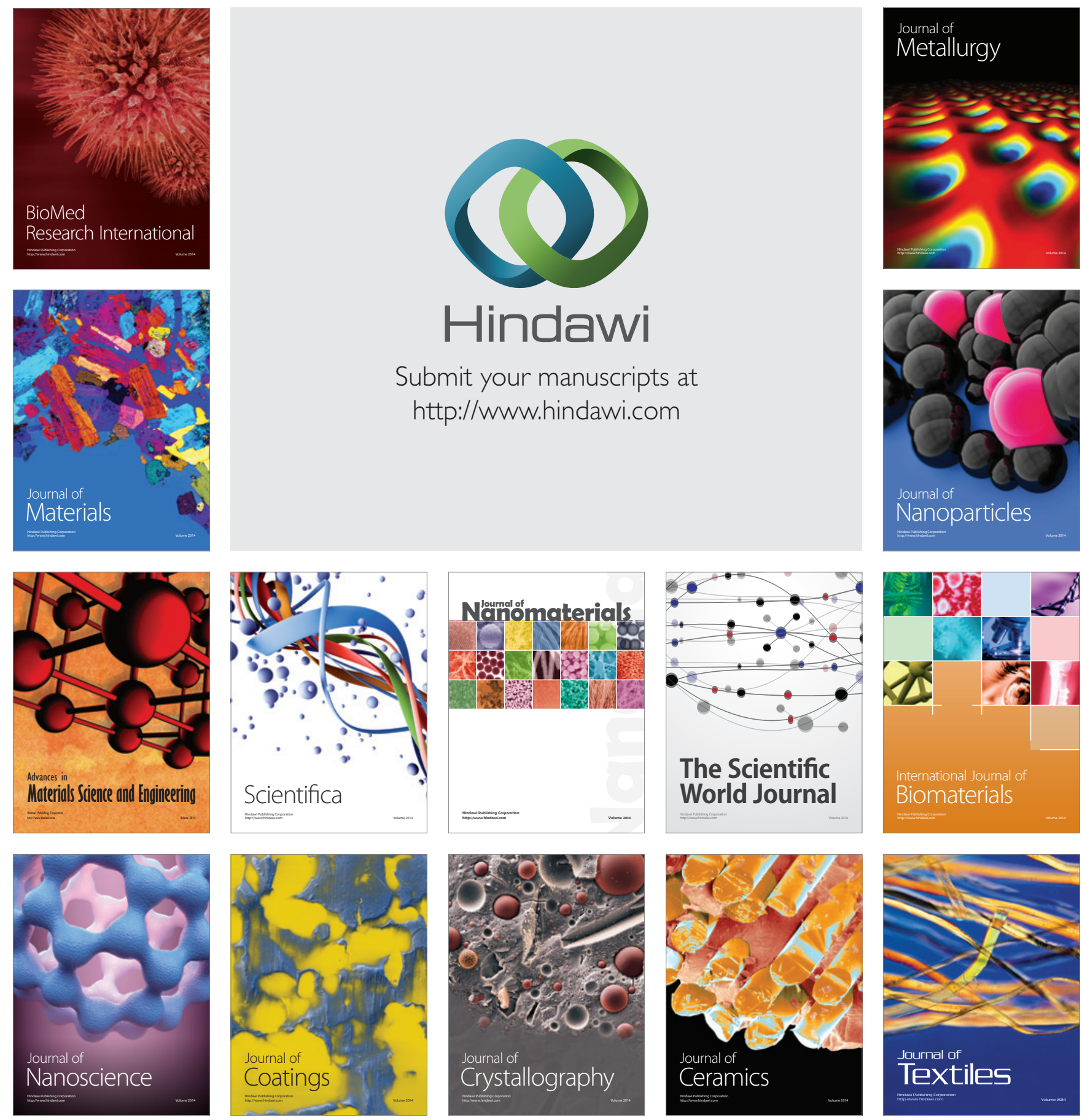